\title{
Conformation of $\beta$-Cyclodextrin-Aromatic Carboxylate Inclusion Complex in Aqueous Solution
}

\author{
Hidefumi Hirai ${ }^{\dagger}$ Yukihide Shiraishi, Hisashi Minori, Kazuhiro Saito, \\ and Tokiji KaWAMUrA* \\ Department of Industrial Chemistry, Faculty of Engineering, Science University of Tokyo, \\ Kagurazaka, Shinjuku-ku, Tokyo 162, Japan \\ * Department of Applied Chemistry, Faculty of Engineering, The University of Tokyo, \\ Hongo, Bunkyo-ku, Tokyo 113, Japan
}

(Received August 2, 1995)

\begin{abstract}
KEY WORDS Inclusion Complex, $\beta$-Cyclodextrin-Benzoate / Inclusion Complex, $\beta$-Cyclodextrin4-Biphenylcarboxylate / Conformation, Inclusion Complex / Nuclear Magnetic Resonance, ${ }^{1} \mathrm{H} /$ Rotating Frame Overhauser Enhancement Spectroscopy / ROESY /
\end{abstract}

We have recently reported the carboxylations of benzoic acid $^{1}$ and 4-biphenylcarboxylic acid ${ }^{2}$ with carbon tetrachloride and copper powder in aqueous alkali by using $\beta$-cyclodextrin ( $\beta$-CyD) as catalyst. The carboxylation of benzoic acid produced terephthalic acid in $74 \mathrm{~mol} \%$ yield with $100 \%$ selectivity. ${ }^{3}$ That of 4-biphenylcarboxylic acid gave 4,4'-biphenyldicarboxylic acid in $71 \mathrm{~mol} \%$ yield with $100 \%$ selectivity. ${ }^{2}$ In the absence of $\beta-\mathrm{CyD}$, however, the carboxylation did not proceed. Thus, the essential factor of the carboxylation is the inclusion complex formation between $\beta$-CyD and the aromatic carboxylate anion in the reaction mixture. The very high selectivity is expected to be ascribed to the conformation of the inclusion complex.

The conformation of cyclodextrin inclusion complex with benzoic acid in aqueous solution has been reported in a few papers. ${ }^{4-7}$ The induced circular dichroism spectroscopy by Kamiya et al. ${ }^{7}$ indicated that a benzoic acid was included axially with a small inclination from the symmetry axis of the $\beta$-CyD cavity, but did not determine the orientation direction of benzoic acid in the cavity of $\beta$-CyD. The formation of the $1: 1$ inclusion complex between $\beta$-CyD and 4-biphenylcarboxylic acid was observed by the fluorescence spectroscopic study by Cho et al. ${ }^{8}$ However, the geometrical information of 4-biphenylcarboxylic acid in the cavity of $\beta$-CyD was not obtained in this literature. ${ }^{8}$

The rotating frame Overhauser enhancement spectroscopy (ROESY) method is useful for measurement of ${ }^{1} \mathrm{H}-{ }^{1} \mathrm{H}$ intermolecular nuclear Overhauser effect on moderately large molecules. ${ }^{9-11}$ In the previous communication, the conformation of $\beta$-CyD-2-naphthalenecarboxylate inclusion complex in aqueous solution was determined by the ROESY method. ${ }^{12}$

We now report the determination of the conformations of $\beta$-CyD-benzoate and $\beta$-CyD-4-biphenylcarboxylate inclusion complexes by measurements of the ${ }^{1} \mathrm{H}$ chemical shifts of $\beta$-CyD and the ROESY spectra on the aqueous alkaline solutions of $\beta$-CyD-benzoic acid and $\beta$-CyD-4biphenylcarboxylic acid, respectively.

\footnotetext{
$\dagger$ To whom correspondence should be addressed
}

\section{EXPERIMENTAL}

The samples for ${ }^{1} \mathrm{H}$ NMR spectra of a solution of $\beta$-CyD $\left(0.1 \mathrm{~mol} \mathrm{~L}^{-1}\right)$ and a solution containing $\beta$-CyD $\left(0.1 \mathrm{~mol} \mathrm{~L}^{-1}\right)$ and benzoate $\left(0.1 \mathrm{~mol} \mathrm{~L}^{-1}\right)$ were prepared in $1 \mathrm{wt} \% \mathrm{NaOD} / \mathrm{D}_{2} \mathrm{O}$ by using benzoic acid as benzoate. Those of a solution of $\beta$-CyD $\left(0.05 \mathrm{~mol} \mathrm{~L}^{-1}\right)$ and a solution containing $\beta$-CyD $\left(0.05 \mathrm{~mol} \mathrm{~L}^{-1}\right)$ and 4-biphenylcarboxylate $\left(0.05 \mathrm{~mol} \mathrm{~L}^{-1}\right)$ were prepared in $0.5 \mathrm{wt} \%$ $\mathrm{NaOD} / \mathrm{D}_{2} \mathrm{O}$ by using 4-biphenylcarboxylic acid as 4-biphenylcarboxylate. The ${ }^{1} \mathrm{H}$ NMR spectra were recorded at $400 \mathrm{MHz}$ on a JNM-GX400 FT-NMR spectrometer at $27.0^{\circ} \mathrm{C}$. Two dimensional (2D) ROESY spectrum was acquired in a sweep width of $2500 \mathrm{~Hz}$. A spin-lock field was used during the mixing period of $1000 \mathrm{~ms}$ and $500 \mathrm{~ms}$ in order to minimize magnetization transfer through scalar couplings. Free induction decays which accumulated 128 times at each mixing time were stored in a matrix of $1024 \times 128$. The data matrix was expanded to $1024 \times 512$ by zero-filling for $F_{1}$-axis and was multiplied by the sinebell window function prior to the double Fourier transform. Chemical shifts are given in parts per million (ppm) downfield from that of tetramethylsilane in chloroform- $d_{1}$ using internal capillary.

\section{RESULTS AND DISCUSSION}

The benzoic acid molecule was converted to benzoate anion in aqueous alkaline solution. The 4-biphenylcarboxylic acid molecule was changed to 4-biphenylcarboxylate anion in aqueous alkali. The C-1-C-6 protons on the glucose unit of $\beta$-CyD are defined as $\mathrm{H}-1-\mathrm{H}-6$, respectively, as shown in Figure 1. The protons of benzoic acid and 4-biphenylcarboxylic acid, respectively, are numbered, as depicted in Figure 1.

The $400 \mathrm{MHz}{ }^{1} \mathrm{H}$ NMR spectrum of a solution containing $\beta$-CyD $\left(0.1 \mathrm{~mol} \mathrm{~L}^{-1}\right)$ and benzoate $\left(0.1 \mathrm{~mol} \mathrm{~L}^{-1}\right)$ was compared with that of a solution of $\beta$-CyD $(0.1$ mol $\mathrm{L}^{-1}$ ). In the presence of benzoate anion, the chemical shifts of $\mathrm{H}-1, \mathrm{H}-2, \mathrm{H}-3, \mathrm{H}-4, \mathrm{H}-5$, and $\mathrm{H}-6$ of $\beta-\mathrm{CyD}$ shifted upfield by $\Delta \delta=0.01,0.00,0.03,0.01,0.06$, and $0.03 \mathrm{ppm}$, respectively. According to the literature, ${ }^{13}$ 
the $\mathrm{H}-3$ and $\mathrm{H}-5$ atoms are directed toward the interior of the cavity of $\beta-\mathrm{CyD}$, whereas the $\mathrm{H}-1, \mathrm{H}-2$, and $\mathrm{H}-4$ atoms are located on the exterior. Thus, the larger changes in the chemical shifts of $\mathrm{H}-3(0.03)$ and $\mathrm{H}-5$ (0.06), compared with those of H-1 (0.01), H-2 (0.00), and $\mathrm{H}-4(0.01)$, indicate that the benzoate anion is included in the cavity of the $\beta$-CyD molecule. The values of ${ }^{1} \mathrm{H}$ chemical shifts of $\beta$-CyD in the absence and presence of 4-biphenylcarboxylate anion was determined by the similar method. In the presence of 4-biphenylcarboxylate anion, the chemical shifts of $\mathrm{H}-1, \mathrm{H}-2, \mathrm{H}-3$, $\mathrm{H}-4, \mathrm{H}-5$, and H- 6 of $\beta$-CyD shifted upfield by $\Delta \delta=0.03$,
$0.02,0.16,0.02,0.24$, and $0.17 \mathrm{ppm}$, respectively. The upfield shifts of the H-3 (0.16) and $\mathrm{H}-5(0.24)$ atoms are remarkably larger than those of $\mathrm{H}-1(0.03), \mathrm{H}-2$ $(0.02)$, and $\mathrm{H}-4(0.02)$ atoms. This fact suggests that the 4-biphenylcarboxylate anion is included in the cavity of $\beta$-CyD. All the values of the upfield shifts of $\beta$-CyD protons in the presence of 4-biphenylcarboxylate anion are considerably larger than those in the presence of benzoate anion. This result is associated with the fact that the magnetic anisotropy effect of the biphenyl group of 4-biphenylcarboxylate is larger than that of the phenyl group of benzoate.

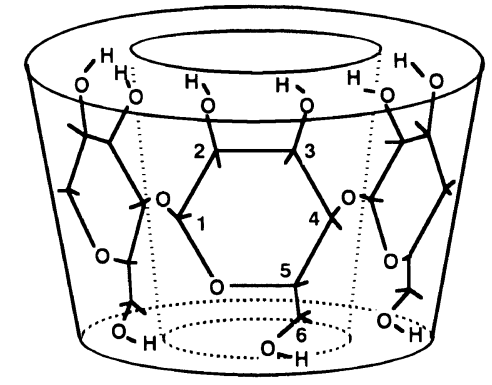

$\beta$-CyD<smiles>O=C(O)c1ccccc1</smiles><smiles>O=C(O)c1ccc(-c2ccccc2)cc1</smiles>

Benzoic acid
4-Biphenylcarboxylic acid

Figure 1. Positional numbers of protons in $\beta$-cyclodextrin $(\beta-\mathrm{CyD})$, benzoic acid, and 4-biphenylcarboxylic acid.

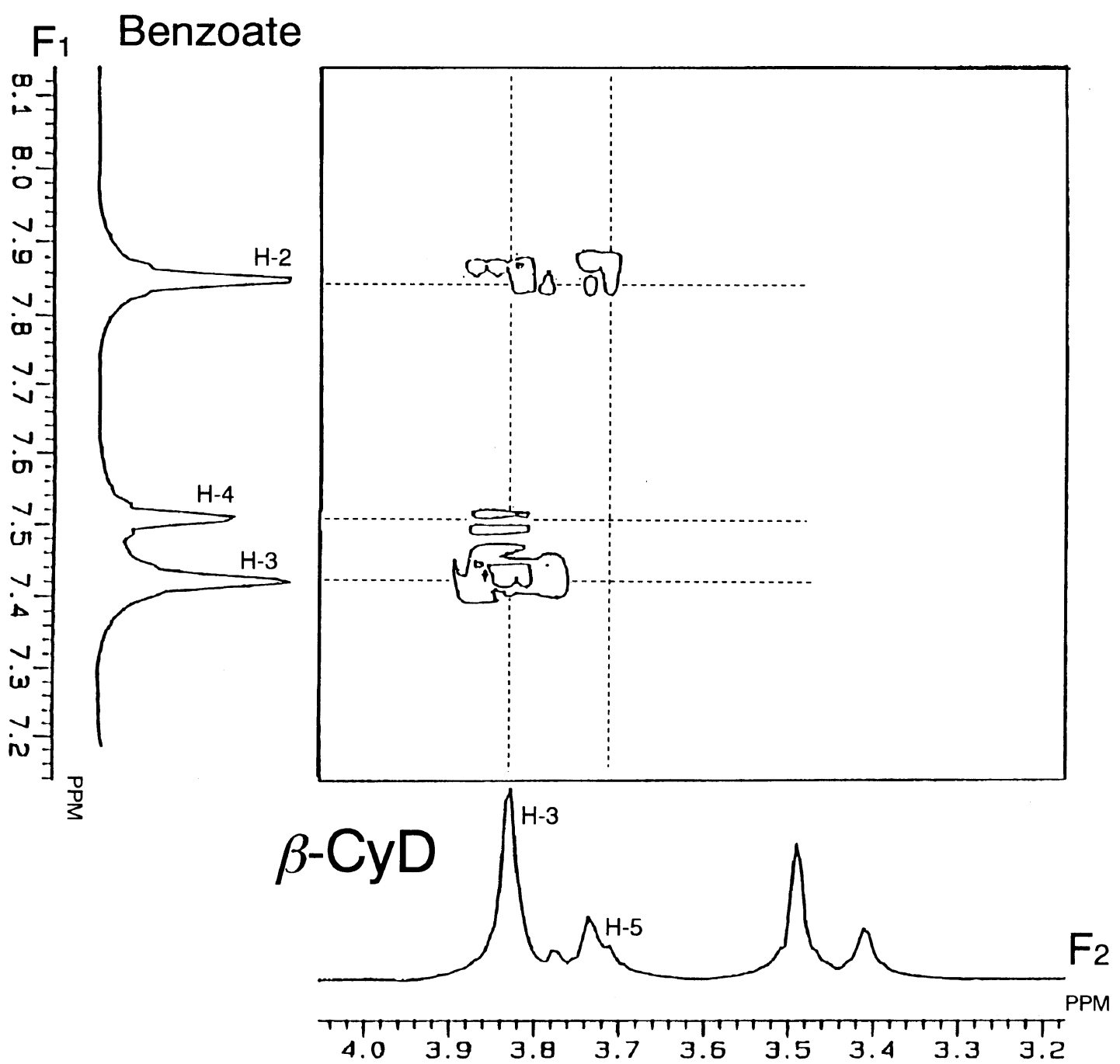

Figure 2. 2D-ROESY spectrum of a solution containing $\beta$-cyclodextrin $\left(0.1 \mathrm{~mol} \mathrm{~L}^{-1}\right)$ and benzoate anion $(0.1 \mathrm{~mol} \mathrm{~L}-1)$ in $1 \mathrm{wt} \% \mathrm{NaOD} / \mathrm{D}_{2} \mathrm{O}$ at $27.0^{\circ} \mathrm{C}$. The projection spectra on the $F_{1}$-axis and $F_{2}$-axis, respectively, were obtained from the $J$-resolved $2 \mathrm{D}$ spectrum. 


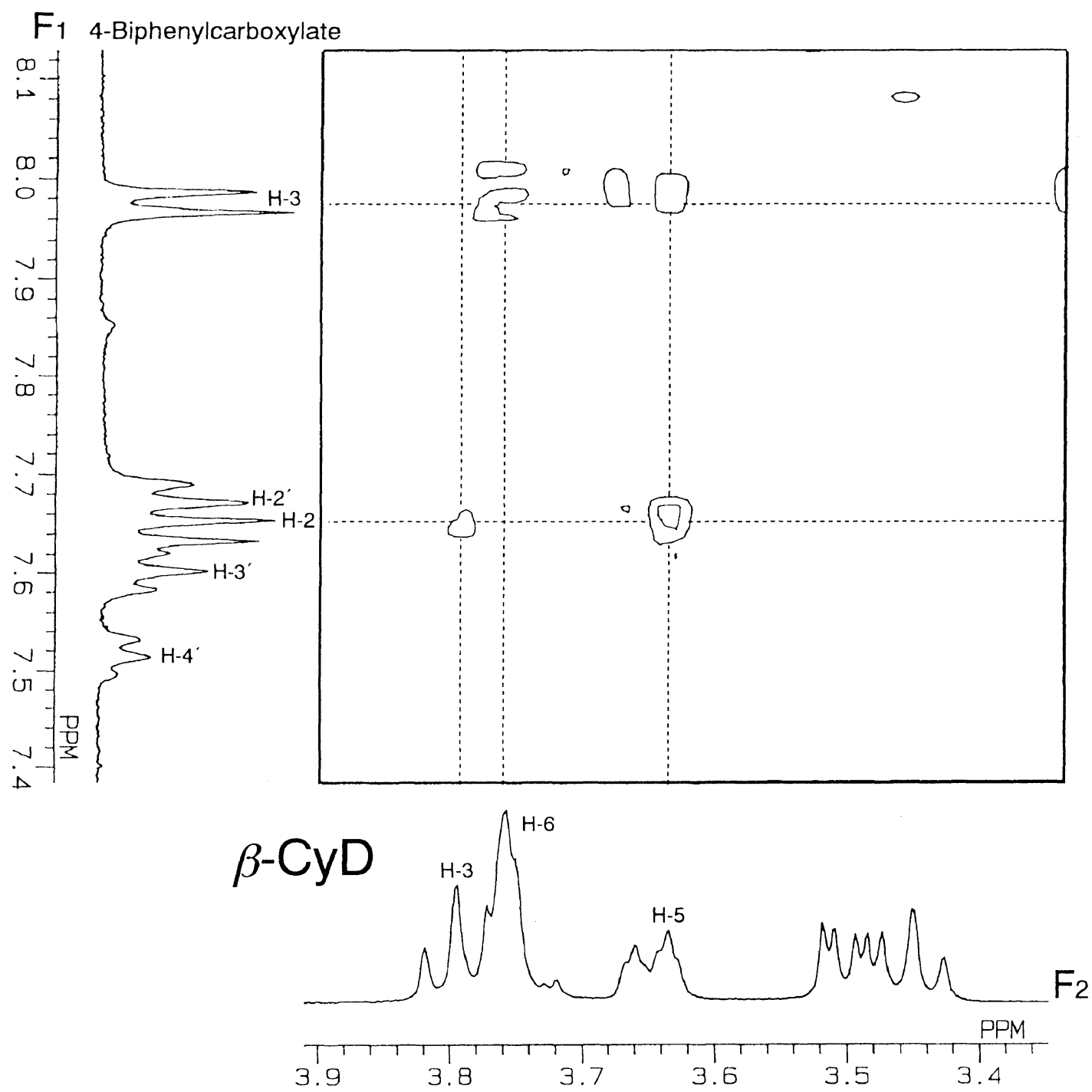

Figure 3. 2D-ROESY spectrum of a solution containing $\beta$-cyclodextrin $\left(0.05 \mathrm{~mol} \mathrm{~L}^{-1}\right)$ and 4-biphenylcarboxylate anion $\left(0.05 \mathrm{~mol} \mathrm{~L}^{-1}\right)$ in $0.5 \mathrm{wt} \%$ $\mathrm{NaOD} / \mathrm{D}_{2} \mathrm{O}$ at $27.0^{\circ} \mathrm{C}$. The projection spectra on the $F_{1}$-axis and $F_{2}$-axis, respectively, were obtained from the $J$-resolved $2 \mathrm{D}$ spectrum.

Figure 2 exhibits the ROESY spectrum of the solution containing $\beta$-CyD and benzoate anion, where the $J$ resolved spectrum of $\beta$-CyD is shown on $F_{2}$-axis and that of benzoate on $F_{1}$-axis. The cross-peak connecting the $\mathrm{H}-3$ resonance of $\beta$-CyD to the $\mathrm{H}-3$ resonance of benzoate is remarkably observed, and that to the $\mathrm{H}-2$ and $\mathrm{H}-4$ resonances of benzoate are observable. The cross-peak connecting the $\mathrm{H}-5$ resonance of $\beta$-CyD to the $\mathrm{H}-2$ resonance of benzoate is appreciable. These results indicate that the $\mathrm{H}-3$ atom of benzoate is situated near the $\mathrm{H}-3$ atom of $\beta$-CyD and the $\mathrm{H}-2$ atom of benzoate lies close to the $\mathrm{H}-5$ atom of $\beta$-CyD. Thus, the conformation of $\beta$-CyD-benzoate inclusion complex in aqueous alkali can be proposed, as shown in Figure 4A. In this figure, $\beta-\mathrm{CyD}$ is illustrated simply by its cavity: the inner diameter of cavity $6.0 \AA$ for the primary hydroxyl side, $6.4 \AA$ for the secondary hydroxyl side, and the depth of the cavity is $7.9 \AA$, according to the literature. ${ }^{14}$ The benzoate anion is axially included in the cavity of $\beta$-CyD with an orientation which locates the carboxylate group at the primary hydroxyl side of $\beta$-CyD and the 4-position of benzoate at the secondary hydroxyl side of $\beta$-CyD.

Figure 3 illustrates the ROESY spectrum of the solution containing $\beta$-CyD and 4-biphenylcarboxylate anion. The cross-peak connecting the $\mathrm{H}-3$ resonance of $\beta$-CyD to the $\mathrm{H}-2$ resonance of 4-biphenylcarboxylate is observable. The cross-peaks connecting the $\mathrm{H}-5$ resonance of $\beta$-CyD to the $\mathrm{H}-2$ and $\mathrm{H}-3$ resonances of 4-biphenylcarboxylate are clearly observed. The crosspeak connecting the $\mathrm{H}-6$ resonance of $\beta-\mathrm{CyD}$ to the $\mathrm{H}-3$ resonance of 4-biphenylcarboxylate is remarkable. These results show that the $\mathrm{H}-2$ atom of 4-biphenylcarboxylate is located between the $\mathrm{H}-3$ and $\mathrm{H}-5$ atoms of $\beta$-CyD and the $\mathrm{H}-3$ atom of 4-biphenylcarboxylate lies close to the $\mathrm{H}-5$ atom of $\beta$-CyD. Figure $4 \mathrm{~B}$ depicts the proposed conformation of $\beta$-CyD-4-biphenylcarboxylate inclusion complex in aqueous alkali. The 4biphenylcarboxylate anion is axially included in the cavity of $\beta$-CyD with an orientation which locates the carboxylate group at the primary hydroxyl side of $\beta$-CyD and the 4'-position of 4-biphenylcarboxylate at the secondary hydroxyl side of $\beta$-CyD. The cross-peaks connecting the proton resonance of $\beta-\mathrm{CyD}$ to the $\mathrm{H}-2^{\prime}$, $\mathrm{H}-3^{\prime}$, and $\mathrm{H}-4^{\prime}$ resonances of 4-biphenylcarboxylate are not observable, as shown in Figure 3. This fact may be due to the location of the $\mathrm{H}-2^{\prime}, \mathrm{H}-3^{\prime}$, and $\mathrm{H}-4^{\prime}$ atoms at the secondary hydroxyl side of $\beta-\mathrm{CyD}$ which has inner 


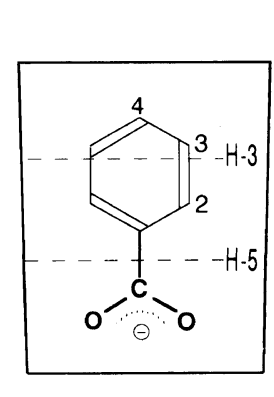

A

Figure 4. Proposed conformations of the $\beta$-cyclodextrin-benzoate inclusion complex $\mathrm{A}$ and the $\beta$-cyclodextrin-4-biphenylcarboxylate inclusion complex B: -.--H-3 and -..--H-5 show planes comprised of the corresponding atoms of $\beta$-cyclodextrin.

diameter $(6.4 \AA)$ of the cavity larger than the primary hydroxyl side of $\beta$-CyD $(6.0 \AA) .{ }^{14}$

The reaction of 4-biphenylcarboxylic acid with carbon tetrachloride and copper powder in aqueous alkali using $\beta$-CyD as catalyst produced $4,4^{\prime}$-biphenyldicarboxylic acid in $71 \mathrm{~mol} \%$ yield with $100 \%$ selectivity. ${ }^{2}$ The 4'-position of 4-biphenylcarboxylate was preferentially attacked by the active species formed from carbon tetrachloride, copper powder and aqueous alkali in this reaction. The reactive sites except for the 4'position of 4-biphenylcarboxylate are enclosed in the cavity of $\beta$-CyD, as shown in Figure 4B. The high selectivity of synthesis of 4,4'-biphenyldicarboxylic acid is probably attributed to the conformation of the $\beta$ CyD-4-biphenylcarboxylate inclusion complex. In the previous communication, ${ }^{1}$ we reported that benzoic acid was converted to terephthalic acid in $75 \mathrm{~mol} \%$ yield with $87 \%$ selectivity by the use of carbon tetrachloride and copper powder in aqueous alkali with $\beta$-CyD as catalyst. Shortly afterward, we examined the optimum amount of $\beta$-CyD, carbon tetrachloride and copper powder, respectively, on the carboxylation of benzoic acid by the use of $\beta$-CyD as catalyst. ${ }^{3}$ In addition, the optimal conditions of high performance liquid chromatography for the product analysis were investigated to improve the separation of each peak. Then, we found that the yield and selectivity of terephthalic acid attained to $74 \mathrm{~mol} \%$ and $100 \%$, respectively. ${ }^{3}$ The benzoate anion included in the cavity of $\beta$ - $\mathrm{CyD}$, as shown in Figure 4A, can be attacked at 4-position selectively by the active species. Thus, the proposed conformations are consistent with the positional selectivity of the carboxylation of benzoic acid and 4-biphenylcarboxylic acid, respectively.

In conclusion, a benzoate anion and a 4-biphenylcarboxylate anion, respectively, are axially included in the cavity of $\beta$-CyD with an orientation which locates the carboxylate group at the primary hydroxyl side of $\beta$-CyD and the 4-position of benzoate and the 4'-position of 4-biphenylcarboxylate, respectively, at the secondary hydroxyl side of $\beta$-CyD.

\section{REFERENCES}

1. H. Hirai and H. Mihori, Chem. Lett., 1523 (1992).

2. H. Hirai, Y. Shiraishi, and K. Saito, Macromol. Rapid Commun., 16, 31 (1995).

3. Y. Shiraishi and H. Hirai, Macromol. Chem. Phys., to be submitted.

4. M. Komiyama and H. Hirai, Polym. J., 13, 171 (1981).

5. R. J. Bergeron, M. A. Channing, and K. A. McGovern, J. Am. Chem. Soc., 100, 2878 (1978).

6. E. Siimer, M. Kurvits, and A. Köstner, Thermochim. Acta, 116, 249 (1987).

7. M. Kamiya, S. Mitsuhashi, M. Makino, and H. Yoshioka, J. Phys. Chem., 96, 95 (1992).

8. D. W. Cho, Y. H. Kim, S. G. Kang, M. Yoon, and D. Kim, J. Phys. Chem., 98, 558 (1994).

9. A. A. Bothner-By, R. L. Stephens, J. Lee, C. D. Warren, and R. W. Jeanloz, J. Am. Chem. Soc., 106, 811 (1984).

10. A. Bax and D. G. Davis, J. Magn. Reson., 63, 207 (1985).

11. W. Saka, Y. Yamamoto, Y. Inoue, R. Chûjô, K. Takahashi, and K. Hattori, Bull. Chem. Soc. Jpn., 63, 3175 (1990).

12. H. Hirai, Y. Shiraishi, H. Mihori, and T. Kawamura, Polym. J., 27, 1064 (1995).

13. P. V. Demarco and A. L. Thakkar, Chem. Commun., 2 (1970).

14. W. Saenger, Angew. Chem., Int. Ed. Engl., 19, 344 (1980). 